\title{
Trends in Suicide Methods and Rates among Older Adults in South Korea: A Comparison with Japan
}

\author{
Subin Park', Hochang Benjamin Lee ${ }^{2}$, Su Yeon Lee ${ }^{3}$, Go Eun Lee ${ }^{4}$, \\ Myung Hee Ahn ${ }^{5}$, Ki Kyoung $\mathrm{Yi}^{5}$, and Jin Pyo Hong ${ }^{6}$ \\ 1'Department of Psychiatry, Seoul National Hospital, Seoul, Republic of Korea \\ ${ }^{2}$ Yale University School of Medicine, New Haven, CT, USA \\ ${ }^{3}$ Department of Mental Health, Johns Hopkins Bloomberg School of Public Health, Baltimore, MD, USA \\ ${ }^{4}$ Department of Psychology, Sungkyunkwan University, Seoul, Republic of Korea \\ ${ }^{5}$ Department of Psychiatry, Asan Medical Center, University of Ulsan College of Medicine, Seoul, Republic of Korea \\ ${ }^{6}$ Department of Psychiatry, Sungkyunkwan University School of Medicine, Samsung Medical Center, Seoul, Republic of Korea
}

Objective Lethality of the chosen method during a suicide attempt is a strong risk factor for completion of suicide. We examined whether annual changes in the pattern of suicide methods is related to annual changes in suicide rates among older adults in South Korea and Japan.

Methods We analyzed annual the World Health Organization data on rates and methods of suicide from 2000 to 2011 in South Korea and Japan.

Results For Korean older adults, there was a significant positive correlation between suicide rate and the rate of hanging or the rate of jumping, and a significant negative correlation between suicide rate and the rate of poisoning. Among older adults in Japan, annual changes in the suicide rate and the pattern of suicide methods were less conspicuous, and no correlation was found between them.

Conclusion The results of the present study suggest that the increasing use of lethal suicide methods has contributed to the rise in suicide rates among older adults in South Korea. Targeted efforts to reduce the social acceptability and accessibility of lethal suicide methods might lead to lower suicide rate among older adults in South Korea.

Psychiatry Investig 2016;13(2):184-189

Key Words Suicide, Crossnational studies, South Korea, Japan.

\section{INTRODUCTION}

In 2012, South Korea had the highest suicide rate of all countries that belong to the Organization for Economic Cooperation and Development (OECD). ${ }^{1}$ Although suicide rates have decreased or remained unchanged in most OECD countries since 1980, suicide has increased rapidly in South Korea over the past 2 decades, particularly among the older adults (age $\geq 65$ ). ${ }^{2}$ According to OECD report in $2009,{ }^{3}$ suicide rates among the older adults aged $65-74$ in South Korea

Received: January 28, 2015 Revised: April 8, 2015

Accepted: May 11, 2015 Available online: October 27, 2015

$\triangle$ Correspondence: Jin Pyo Hong, MD, PhD

Department of Psychiatry, Sungkyunkwan University School of Medicine, Samsung Medical Center, 81 Irwon-ro Gangnam-gu, Seoul 06351, Republic of Korea

Tel: +82-2-3410-3585, Fax: +82-2-3410-0050

E-mail: suhurhong@gmail.com

(a) This is an Open Access article distributed under the terms of the Creative Commons Attribution Non-Commercial License (http://creativecommons.org/licenses/bync/3.0) which permits unrestricted non-commercial use, distribution, and reproduction in any medium, provided the original work is properly cited. was $81.8 / 100,000$, which are about 6 times higher than those in the United States (US) $(14.1$ per 100,000) and about 17 times higher than those in the United Kingdom. Aging of South Korean population is also projected to be the most rapid among OECD countries. ${ }^{4}$ Therefore, the high suicide rate among older adults has become an alarming public health issue in South Korea.

The lethality of the chosen suicide method is the strongest risk factor for suicide completion. ${ }^{5,6}$ Use of firearms and hanging are two of the most lethal suicide methods with over $80 \%$ case fatality while self-poisoning and self-injurious behavior with sharp objects having lower fatality (less than 5\%). ${ }^{6,7}$ Therefore, a trend toward increased use of more lethal suicide methods among older adults may partially explain the increase in suicide rates among elders over time in South Korea.

In the present study we examined the association between the annual change in the pattern of suicide methods and the annual change in suicide rates among older adults in South Korea. Also, we compared the trends in suicide rates and 
methods among older adults across South Korea and Japan. Japan is selected as the comparison group because South Korea and Japan are neighboring countries and share similar social contexts, as well as demographic transitions which caused rapid population aging. ${ }^{8}$ We hypothesized that the increased use of more lethal methods may be related to the annual increase in suicide rates among older adults.

\section{METHODS}

\section{Data and procedures}

Data on suicide rates and methods in South Korea and Japan were obtained from the World Health Organization (WHO) mortality database. ${ }^{9}$ We analyzed the annual data during the period of 2000-2011 to examine the trends in suicide rates and suicide methods in two countries. Suicide methods were classified into six categories according to the ICD-10 codes: self-poisoning (X60-X66, X68-69), charcoal burning (X67), hanging (X70), jumping from a high place (X80), and others (X71, X72-X79, X81-X84).
The WHO obtained data on deaths including age, sex, and cause of death, as reported annually by member states through civil registration systems (e.g., the Korean National Statistical Office and the Statistics Bureau and the Director-General for Policy Planning of Japan), and compiled the data in the WHO mortality database. Based on country-reported data and the use of additional data sources such as population censuses and household surveys, the WHO and its partners regularly estimated key mortality statistics to improve data comparability across countries and years. In addition, the WHO estimated the completeness and coverage of reported data, and assesses the quality of cause-of-death data. According to the $\mathrm{WHO}$, the rate of civil registration coverage of cause of death was $100 \%$ in both countries. The rate of ill-defined causes in cause-of-death registration was $15.4 \%$ in South Korea and 8.6\% in Japan in 2011.

The study protocol was approved by the Institutional Review Board or Ethics Committee of Asan Medical Center, Seoul, Republic of Korea (2012-0605) and all procedures were conducted in accordance with the Helsinki Declaration

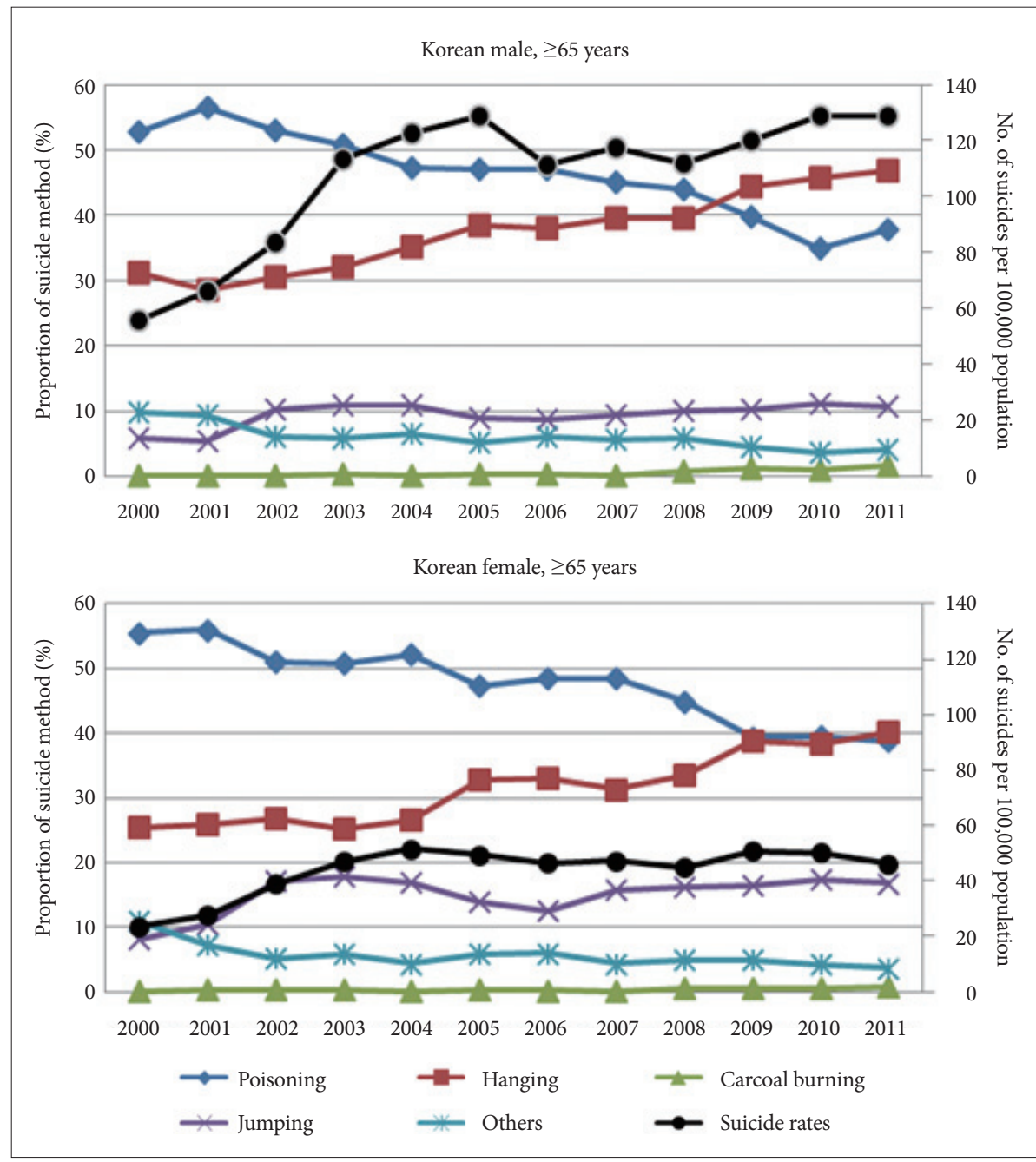

Figure 1. Annual trends in suicide rates and the suicide methods in South Korea between 2000 and 2011 . With the increase in suicide rates, the rate of hanging increased and the rate of self-poisoning steadily decreased in Korean older people. 
of 1975 , as revised in 2000 .

\section{Statistical analysis}

We examined correlations between the proportion of specific suicide methods and suicide rates of each calendar year in South Korea between 2000 and 2011 and Japan between 2001 and 2011. All statistical analyses were performed using SPSS (version 21.0; SPSS Inc., Chicago, IL, USA), with statistical significance defined as an alpha level of $0.05 / 5$ suicide methods $=0.01$.

\section{RESULTS}

Annual suicide rates and the proportion of suicide methods over 65 years of age in South Korea between 2000 and 2011 are shown in Figure 1. During this period, suicide rates for males rapidly increased from 55.6 to 128.6 suicides per 100,000 individuals, and suicide rates for females increased from 23.6 to 46.1 suicides per 100,000 individuals. In South Korea, self-poisoning was the most common method of sui- cide for both male and female older people until the late 2000 's, but the rate of self-poisoning steadily decreased since 2001. In contrast, the rate of hanging and the rate of charcoal burning increased, and hanging has been the most common method of suicide among Korean older adults since 2009. For Korean older males, there was a significant positive correlation between suicide rate and the rate of hanging [correlation coefficient $(r)=0.77, p=0.003$ ] and the rate of jumping $(\mathrm{r}=0.81, \mathrm{p}=0.001)$, and a negative correlation between suicide rate and the rate of poisoning $(\mathrm{r}=-0.81, \mathrm{p}=0.002)$. For Korean older females, there was a significant positive correlation between suicide rate and the rate of jumping $(r=0.79, p=0.002)$, and a trend of negative correlation between suicide rate and the rate of poisoning $(\mathrm{r}=-0.67, \mathrm{p}=0.018)$.

Annual suicide rates and the proportion of suicide methods over 65 years of age in Japan between 2001 and 2011 are shown in Figure 2. Suicide rates of Japanese adults aged 65 years or older were steadily decreased from 46.8 to 38.5 suicides per 100,000 individuals for males and from 23.3 to 18.6 suicides per 100,000 individuals for females. During the study

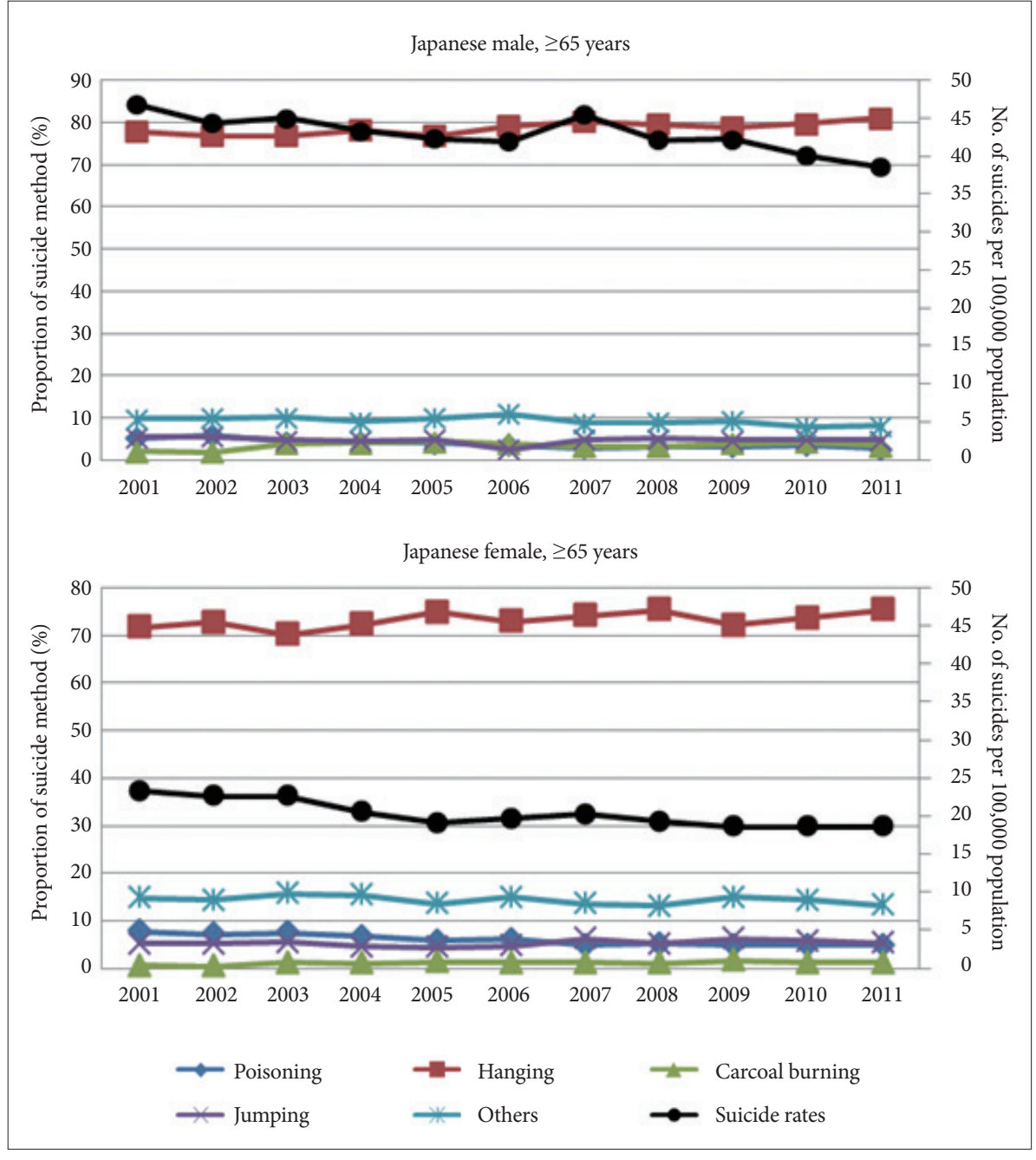

Figure 2. Annual trends in suicide rates and the suicide methods in Japan between 2001 and 2011. Suicide rates and the pattern of suicide methods have changed little in Japanese older people. 
period, hanging was the most common method of suicide for both male and female older people in Japan. Among older adults in Japan, annual changes in the pattern of suicide methods were less conspicuous, and no correlation was found between the proportion of specific suicide methods and suicide rates.

\section{DISCUSSION}

The strength of this study is a cross-national comparison of suicide rates and methods over a decade and high reliability of data collection on suicide statistics across countries. We hypothesized that the increased use of more lethal methods may be associated with the annual increase in suicide rates among older adults in South Korea. This hypothesis is partially supported by our study findings.

Annually, the proportion of more lethal method (i.e., hanging) increased and the proportion of less lethal method (i.e. poisoning) decreased among males and females aged 65 years or older in South Korea. This trend in increased use of more lethal suicide method correlated with increased annual suicide rates among male elders. However, there was no association between the annual changes in proportion of lethal methods and overall suicide rates among Japanese older adults.

This difference between countries, significant association between the proportion of lethal methods and suicide rates in Korean older adults, but no association in Japanese older adults, might be partially explained by the fact that the pattern of suicide methods has changed drastically in South Korea, but it has changed very little in Japan during the study period.

Another consideration is the socio-cultural factors affecting attitudes towards aging and death. Suicide rates in South Korea surpassed those in Japan after 2000, mainly because of a steep increase in suicide rates among older adults. ${ }^{10}$ From being an agricultural society, South Korea underwent drastic social, cultural, and economic changes, including industrialization and urbanization since the 60 's. ${ }^{11}$ Other changes in South Korean society, accompanied by industrialization and urbanization, include a shift from a larger extended family to a nuclear family and a trend away from Collectivism to individualism. ${ }^{12}$ These changes are indicative of diminishing availability of households that care for older relatives, increase in intergenerational frictions, and lower status of older people in the family. Yet, Korean healthcare or social welfare system is not adequately prepared for the increasing demand of elderly care. ${ }^{11}$ Consequently, as longevity increases, many older adults with multiple medical illnesses and poor social support live longer and have little earning potential, which could increase the risk of suicide. ${ }^{13}$ These older people might choose more lethal methods for suicide, because they have a fear of being burden on family after failing at committing suicide (e.g., being disabled, medical expenses for hospitalization and treatment). Although Japan underwent similar social changes and similarly faces the issue of population aging, its relatively well-developed social welfare program for older adults may have supported older people and prevented an upsurge in suicides. ${ }^{14,15}$

Government should foster social policies that focus on sustaining the quality of life for Korean older people. It is necessary to develop a Korean infrastructure for retired, low-income, and socially isolated older adults. Stepped care for older adults with depressive symptoms and substance use, through collaborative team efforts between primary and specialty care practitioners, case managers, and nurses can decrease depressive symptoms and suicidal risk among older people. ${ }^{16}$ Other problem-solving methods for intergenerational conflicts and retirement preparation (finances, housing, etc.) could be useful for preventing suicide among older adults in South Korea. Community-based suicide prevention programs conducted in Japan, including depression screening with follow-up and health education through primary care and public health nursing, significantly reduced suicide rates for female older adults. ${ }^{17-19}$

Until 2003, self-poisoning had been the most accessible and common form of suicide method in South Korea. However, due to recent pharmacy laws that have restricted dispensing of prescription medications, potentially lethal medications have become less available to suicidal patients in recent years. ${ }^{20}$ In 2000, the Pharmacist Law was revised to specify that only pharmacists can supply pharmaceuticals to the public, with the separation of prescribing and dispensing designed to prevent the prescription of unnecessary drugs. In addition, several policies have been enacted to limit access to paraquat, a highly toxic pesticide that has been associated with both accidental and intended deaths in South Korea. In 1997, the Agrochemicals Control Act limited paraquat sales and purchases, and the law was revised in 2005 to make it stricter. This may explain an increased use of hanging, a more readily available method. These findings suggest that government restrictions limiting pesticide purchases and prescription medications may have been effective strategies for reducing suicide by these methods, ${ }^{21}$ but challenges remain for the regulation of suicide methods, such as hanging. ${ }^{22}$

Poor compliance of media reporting guidelines on suicide in South Korea and its glorified portrayal on television or newspaper may contribute to high social acceptability of hanging, resulting an increase of hanging suicides. Between 2005 and 2008, there were four female celebrity suicides by hanging. ${ }^{23}$ Those deaths were prominently publicized along with a subsequent sharp increase in suicide rates by hanging. ${ }^{24}$ Suicide by hanging was influenced by distorted public perception 
of the acceptability of this approach. ${ }^{25,26}$ The media plays an important role in determining public perceptions of the acceptability of certain suicide methods ${ }^{27,28}$ and influence of media on public perception is more paramount in South Korea, which has the highest TV and the Internet penetration rate in the world. Suicide prevention agencies should foster innovative strategies to collaborate with media professionals and improve health promotions through web-based programs to reduce the socio-cultural acceptability of hanging. ${ }^{29}$

Recent increase in suicide rates by charcoal burning may be also influenced by mass media. In Korea, In Korea, prior to 2008, charcoal burning was a lesser-known method of suicide. However, when a middle-aged male celebrity with financial problems in Korea committed suicide by burning charcoal in an enclosed car in 2008, the charcoal burning method was vividly reported by the media and then became widely used with increasing frequency. In particular, as the charcoal burning suicide method was new in Korea, the media coverage offered detailed descriptions of the suicide instrument and process and was likely to have contributed greatly to the increase in suicides by charcoal burning. Therefore, it is critical to prevent the new method of suicide from being described to the public through media reports. ${ }^{30,31}$ Suicide by charcoal burning may also be preventable to some extent by limiting physical availability of charcoal. Yip et al. ${ }^{32}$ reported that the suicide rate from charcoal burning was significantly reduced in the intervention region, in which all charcoal packs were removed from the open shelves of major retail outlets, but not in the control region, in which charcoal packs were displayed as usual.

We must cautiously interpret the results of this study within the context of the following limitations. First, government case registries may underestimate the number of deaths due to suicide because many suicides may have been classified as "undetermined" deaths. ${ }^{33,34}$ According to the WHO, the rate of ill-defined cause of death was higher in South Korea (15.4\%) than in Japan (8.6\%). This means that the number of suicides might be underestimated in South Korea compared with Japan. Second, the suicide rate has changed more in South Korea than in Japan during the study period, which may affect the significant association between the pattern of suicide methods and suicide rate in South Korea, but non-significant association in Japan. Third, correlation was used for all the years rather than spline terms or other time-based measures. Forth, even though our focus was on the impact of suicide methods on annual changes in suicide rates, various other factors may have influenced the annual change in overall suicide rates, including social, economic, and physical situations which were not considered. Finally, because there was no national census data on rates of attempted suicide corresponding to the WHO data on suicide mortality, we could not analyze the correlations between the proportion of specific methods of suicide attempt and suicide rates directly. Therefore, future studies that use data on methods of suicide attempt as well as death by suicide are required to corroborate these results.

Our present findings suggest that the increased use of lethal suicide methods in South Korea is associated with an increase in the overall suicide rate among Korean older adults. While regulating less lethal methods of suicide, such as poisoning, was relatively successful in South Korea over the past decade, challenges remain in the prevention of suicide by hanging, which has high case fatality and accessibility. Targeted efforts to reduce the social acceptability and accessibility of lethal suicide methods along with implementation of social welfare programs and community-based suicide prevention programs might lead to lower suicide rate among older adults in South Korea.

\section{Acknowledgments}

This work was supported by the Korea Healthcare Technology R\&D project, Ministry of Health \& Welfare, Republic of Korea (grant number A120051).

\section{REFERENCES}

1. OECD. OECD Health Data 2012. Available from: www.who.int/ healthinfo/statistics/mortality/en/index1.html. Accessed Oct 16, 2014.

2. Chiu HF, Takahashi Y, Suh GH. Elderly suicide prevention in East Asia. Int J Geriatr Psychiatry 2003;18:973-976.

3. OECD. Health at a Glance 2009. Available from: www.oecd.org/ health/health-systems/44117530.pdf. Accessed Oct 16, 2014.

4. Yoon HS. Korea: balancing economic growth and social protection for older adults. Gerontologist 2013;53:361-368.

5. Marzuk PM, Leon AC, Tardiff K, Morgan EB, Stajic M, Mann JJ. The effect of access to lethal methods of injury on suicide rates. Arch Gen Psychiatry 1992;49:451-458.

6. Spicer RS, Miller TR. Suicide acts in 8 states: incidence and case fatality rates by demographics and method. Am J Public Health 2000;90: 1885-1891.

7. Shenassa ED, Catlin SN, Buka SL. Lethality of firearms relative to other suicide methods: a population based study. J Epidemiol Community Health 2003;57:120-124.

8. Kim IK, Maeda D. A comparative study on sociodemographic changes and long-term health care needs of the elderly in Japan and South Korea. J Cross Cult Gerontol 2001;16:237-255.

9. WHO. WHO mortality data and statistics. Available from: http://www. who.int/healthinfo/statistics/mortality_rawdata/en/index.html. Accessed Oct 16, 2014.

10. Kim SY, Kim MH, Kawachi I, Cho Y. Comparative epidemiology of suicide in South Korea and Japan: effects of age, gender and suicide methods. Crisis 2011;32:5-14.

11. Palley HA. Social policy and the elderly in South Korea: confucianism, modernization, and Development. Asian Survey 1992;32:787-801.

12. Jiloha RC. Impact of modernization on family and mental health in South Asia. Delhi Psychiatry J 2009;12:42-60.

13. Im JS, Choi SH, Hong D, Seo HJ, Park S, Hong JP. Proximal risk factors and suicide methods among suicide completers from national suicide mortality data 2004-2006 in Korea. Compr Psychiatry 2011;52: 231-237.

14. Chen J, Choi YJ, Sawada Y. How is suicide different in Japan? JPN World 
Eco 2009;21:140-150

15. Inagaki $S$. The effects of proposals for basic pension reform on the income distribution of the elderly in Japan. Rev Socionetwork Strat 2010; 4:1-16.

16. Lapierre S, Erlangsen A, Waern M, De Leo D, Oyama H, Scocco P, et al. A systematic review of elderly suicide prevention programs. Crisis 2011;32:88-98.

17. Oyama H, Goto M, Fujita M, Shibuya H, Sakashita T. Preventing elderly suicide through primary care by community-based screening for depression in rural Japan. Crisis 2006;27:58-65.

18. Oyama H, Sakashita T, Ono Y, Goto M, Fujita M, Koida J. Effect of community-based intervention using depression screening on elderly suicide risk: a meta-analysis of the evidence from Japan. Community Ment Health J 2008;44:311-320.

19. Oyama H, Watanabe N, Ono Y, Sakashita T, Takenoshita Y, Taguchi M, et al. Community-based suicide prevention through group activity for the elderly successfully reduced the high suicide rate for females. Psychiatry Clin Neurosci 2005;59:337-344.

20. Lee WJ, Cha ES, Park ES, Kong KA, Yi JH, Son M. Deaths from pesticide poisoning in South Korea: trends over 10 years. Int Arch Occup Environ Health 2009;82:365-371.

21. Leenaars A, Cantor C, Connolly J, EchoHawk M, Gailiene D, He ZX, et al. Controlling the environment to prevent suicide: international perspectives. Can J Psychiatry 2000;45:639-644.

22. Ohberg A, Lonnqvist J, Sarna S, Vuori E, Penttila A. Trends and availability of suicide methods in Finland. Proposals for restrictive measures. Br J Psychiatry 1995;166:35-43.

23. Jeong J, Shin SD, Kim H, Hong YC, Hwang SS, Lee EJ. The effects of ce- lebrity suicide on copycat suicide attempt: a multi-center observational study. Soc Psychiatry Psychiatr Epidemiol 2012;47:957-965.

24. Korea National Statistical Office. National Statistics Report. Seoul: Korea National Statistical Office; 2009.

25. Biddle L, Donovan J, Owen-Smith A, Potokar J, Longson D, Hawton K, et al. Factors influencing the decision to use hanging as a method of suicide: qualitative study. Br J Psychiatry 2010;197:320-325.

26. Cantor CH, Baume PJ. Access to methods of suicide: what impact? Aust N Z J Psychiatry 1998;32:8-14.

27. Biddle L, Gunnell D, Owen-Smith A, Potokar J, Longson D, Hawton K, et al. Information sources used by the suicidal to inform choice of method. J Affect Disord 2012;136:702-709.

28. Hawton K, Williams K: Influences of the media on suicide. BMJ 2002; 325:1374-1375.

29. Kreps GL, Neuhauser L. New directions in eHealth communication: opportunities and challenges. Patient Educ Couns 2010;78:329-336.

30. Chen YY, Chen F, Gunnell D, Yip PS. The impact of media reporting on the emergence of charcoal burning suicide in Taiwan. PLoS One 2013; 8:e55000.

31. Tsai CW, Gunnell D, Chou YH, Kuo CJ, Lee MB, Chen YY. Why do people choose charcoal burning as a method of suicide? An interview based study of survivors in Taiwan. J Affect Disord 2011;131:402-407.

32. Yip PS, Law CK, Fu KW, Law YW, Wong PW, Xu Y. Restricting the means of suicide by charcoal burning. Br J Psychiatry 2010;196:241-242.

33. Evenson RC, Cho DW, Holland R. Identifying psychiatric suicides for research purposes. J Clin Psychol 1988;44:1029-1032.

34. Marusic A, Roskar S, Zorko M. Undetermined deaths: are they suicides? Croat Med J 2003;44:550-552. 